\title{
An Eco-friendly Approach of Cotton Fabric Dyeing with Natural Dye Extracted from Bixa orellana Seeds Employing Different Metallic Mordants
}

\author{
Nasim-Uz-Zaman, Md. Luthfar Rahman Liman*, Abdul Kader, Md. Abdullah Al Mamun, \\ Bappi Sarker, Rafiul Islam, Israt Parveen
}

Department of Textile Engineering, Mawlana Bhashani Science and Technology University (MBSTU), Bangladesh

Copyright@2018 by authors, all rights reserved. Authors agree that this article remains permanently open access under the terms of the Creative Commons Attribution License 4.0 International License

\begin{abstract}
The aim of this project work is to study the application of Bixa orellana seed for dyeing of cotton knitted fabric. To satisfy the future demand for an eco-friendly as well as sustainable dyeing of cotton fabric numeric exploration had been performed in this work. Natural dye was extracted by normal water extraction method with caustic soda from raw seed of Bixa orellana. In this experiment commercially scoured-bleached $100 \%$ cotton knitted single jersey structure fabric with an areal density of 140 grams per square meter is used. Pre-mordanting action of cotton fabric samples were carried out using various metallic salts. Samples were dyed using by Glauber Salt + hot wash with Standard Soap, without Glauber Salt + hot wash, Glauber Salt + without hot wash and without Glauber Salt + without hot wash. Color strength of the dyed samples for different dyeing condition was assessed by means of K/S value. To intensify the color strength various mordanting agents were used. Effect of mordanting agents had evaluated by means of K/S value. Best color strength was yield for the samples dyed with Bixa orellana which were mordanted with $\mathrm{CuSO}_{4}$. Impact of electrolyte on color strength had also investigated by means of K/S value. Color fastness of the selected dyed samples to water, washing, perspiration and rubbing were evaluated. Impact of mordanting agents, hot wash and electrolyte were intensively evaluated. In all cases mordanted samples with $\mathrm{CuSO}_{4}$ exhibit best result. This result adumbrates developing a sustainable technology for a cabalistic utilization of Bixa orellana seed for coloration of cotton knitted fabric. The exquisite assessment of all tested properties of colored samples evolves this technology can be commercially implemented by considering few limitations.
\end{abstract}

Keywords Bixa orellana, Mordanting Agents, K/S Value, Color Fastness

\section{Introduction}

Nowadays being fashionable means to be worried about environmental issues and sustainable development [1]. Dyes which extracted from natural materials such as plant leaves, roots, bark, insect secretions, and minerals for sustainable and eco-friendly textile dyeing are now become lessening the exercise of synthetic dyes in the global industrial markets. Recently the awareness of environment as well as increasing disputes about the risks of synthetic dyes resulted in growing interest in natural resources, environmentally friendly products and new strategies. Green Chemistry is the design, development, and implementation of chemical products and processes to reduce or eliminate the use and generation of substances hazardous to human health and the environment [2]. Textile processing industry is one of the major environmental polluters. In order to process a ton of textile about 230-270 tons of water is spent by generating an effluent proportional to this quantity [3]. The predominance of synthetic dyes in the last decades harmed the development and adaptation of natural dyeing to the needs of modern textile industries [4]. Naturally colored cotton is therefore seen as a substitute raw material ensuring ornamentation of textiles without use of highly toxic dyes and chemicals and hence in this direction annatto seeds (Bixa orellana) were selected as a natural dye source for cotton knitted fabric. Annual world production of dried annatto seed at the beginning of the 21st century was estimated at about 10,000 tons, of which 7,000 tons enter international trade. Annatto dye is basically a red orange pigment known as Bixin, extracted from the seed coat of Sinduri, contains carotenoid of various types out of which cis-bixin alone accounts for $82 \%$ chemistry and performance of annatto colors is essentially of the bixin. Bixin is highly unsaturated compound. The bixin dissolves in vegetable oil, undergoes isomerization and degradation reactions when heated. Standardization of the medium for 
dye extraction .Annatto dye was extracted in alkaline, alcoholic and in aqueous medium. This dye requires the formation of a metal-fiber complex to fix the dyes to the fiber and the choice of the mordant affects the final color of the fabrics. A natural dye mordant could be any one of several metal salts capable of providing a chemical bond between fiber and dye [5]. They bond with dyes more easily than the fiber and improve the color fastness of the dyed fabrics. The effect of ammonia post-treatment on Wool yarns dyed with extract from Annatto seeds [6]. For this purpose the woolen yarn samples dyed with annatto were treated with various ammonia solutions $(1,3$, and $5 \%$ $\mathrm{w} / \mathrm{w})$ at $25^{\circ} \mathrm{C}$ for 10 mins. It was established that the treatment with ammonia solution results in a variety of sober and elegant shades with variation in hue and tone. It is found that the highest color depth $(\mathrm{K} / \mathrm{S})$ on woolen yarn was obtained by using $5 \%(\mathrm{w} / \mathrm{v})$ ammonia concentration. Extracting the coloring compounds from the fabric prior to analyzing by spectroscopic techniques is required to identify natural dyes in historic textiles and used a mixture of ethanol and hydrochloric acid for the hydrolysis stage[7] as well as Chloro-solvents such as dichloromethane can be used for direct extraction[8]. So, the main goal of this work is to quantify dyeing temperature for reasonable green coloration of cotton fabric as well as evaluate the optimum $\mathrm{K} / \mathrm{S}$ value, color fastness properties of treated samples which exhibit good sustainable coloring performance with different mordanting salts.

\section{Experimental}

\subsection{Materials and Methods}

\subsubsection{Materials}

$100 \%$ single jersey cotton knitted single jersey fabric was collected from Comfit Composite Knit Ltd., Gorai, Mirzapur, Tangail, Dhaka, Bangladesh. Areal density of the fabric was $140 \mathrm{~g} / \mathrm{m}^{2}$.

\subsubsection{Dyes and Chemicals}

Caustic soda $(\mathrm{NaOH})$ and water are used. For mordanting various metallic are salt used. Such as Iron(II) Sulphate- $\mathrm{FeSO}_{4}$, Iron(III) Chloride- $\mathrm{FeCl}_{3}$, Copper(II) Sulphet-CuSO${ }_{4} \cdot 5 \mathrm{H}_{2} \mathrm{O}$ and Alum- $\mathrm{Al}_{2} \mathrm{~K}_{2}\left(\mathrm{SO}_{4}\right)_{4}$. All mordanting agents were collected from Merck, Germany laboratory grade and used without any further purification. Color from Bixa orellana seed is used as natural dye and the seeds were collected from Noakhali Science and Technology University, Noakhali, Bangladesh. ISO Standard Soap used for removing the unfixed dye from dyed sample.

\subsection{Methods}

\subsubsection{Sampling Plan}

Different samples are identified as tabulated in table 1.

\subsubsection{Natural Dye Extraction Process}

At first the Bixa orellana seeds were collected from the Bixa orellana fruit and then the seeds were dried properly in the sun light. In order to extract $10 \mathrm{gm}$ dye, Bixa orellana seeds were taken by measured from the balance and $500 \mathrm{cc}$ water was taken by measured by the measuring cylinder. Then boiled the Bixa orellana seeds, water together with $2 \mathrm{gm}$ caustic soda at $100^{\circ} \mathrm{C}$ about 60 minutes and cooled and then stored overnight. In the next day, fresh 500cc water was mixed with the dye liquor. The extracted dye liquor prepared for dyeing by strained through the nylon strainer.

Table 1. Nomenclature of specimens

\begin{tabular}{|c|c|}
\hline Sample types & Identification \\
\hline Iron (II) sulphate treated sample, $\mathrm{FeSO}_{4}$ & A \\
\hline Iron (III) sulphate treated sample, $\mathrm{FeCl}_{3}$ & B \\
\hline Copper(II) sulphate treated sample, $\mathrm{CuSO}_{4} \cdot 5 \mathrm{H}_{2} \mathrm{O}$ & $\mathrm{C}$ \\
\hline Potassium alum treated sample, $\mathrm{AlK}\left(\mathrm{SO}_{4}\right)_{2} \cdot 12 \mathrm{H}_{2} \mathrm{O}$ & D \\
\hline
\end{tabular}
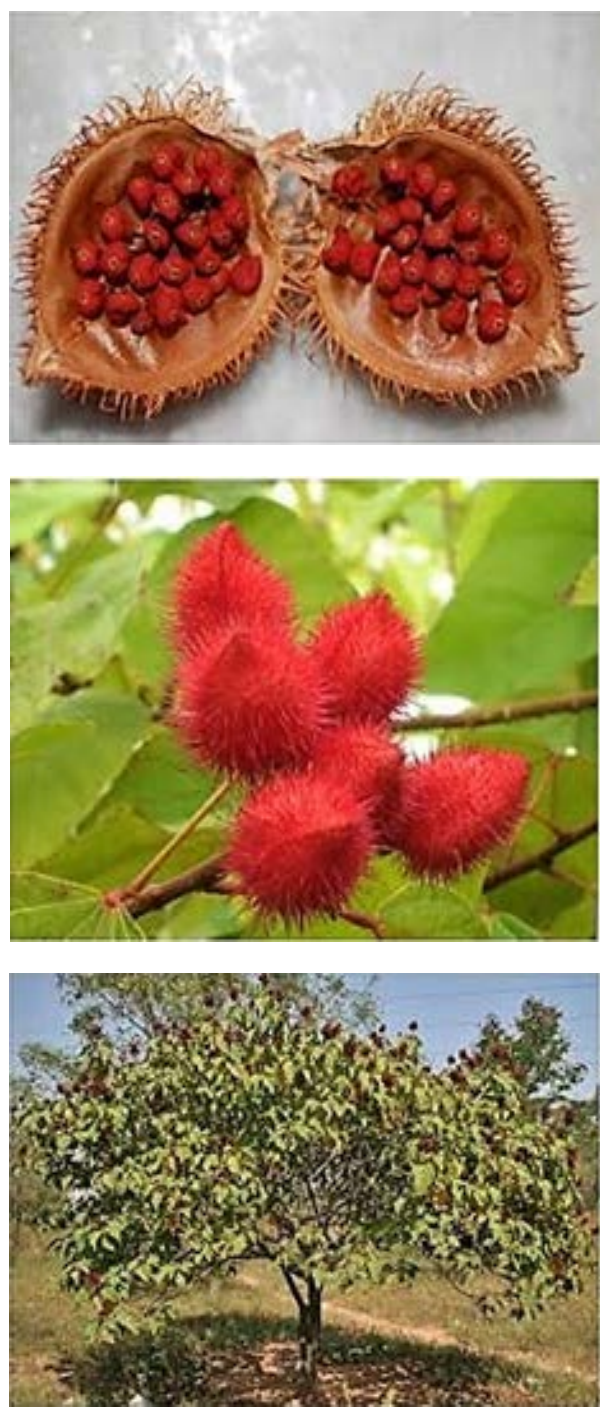

Figure 1. Different parts of Bixa orellana seed 
<smiles>COC(=O)/C=C/C(C)=C\C=C\C(C)=C\C=C\C=C(C)\C=C\C=C(C)\C=C\C(=O)O</smiles>

cis-Bixin

Figure 2. Structure of Bixin

\subsubsection{Mordanting}

To promote the dye uptake, cotton specimens were treated with various positively charged metallic salts. Figure expresses the chelating between cellulose and $\mathrm{Al}^{3+}$ via co-ordination linkage. Cotton fabric samples were subjected to pre-mordanting with $5 \mathrm{~g} / \mathrm{L}$ metallic mordants at $100^{\circ} \mathrm{C}$ for $60 \mathrm{mins}$. Figure represents the process curve of pre-mordanting action. After mordanting action samples were impregnated into bath for overnight. Then the mordanted samples were squeezed and air dried in flat dryer machine (MESDAN, Italy).The materials to liquor rate were maintained as 1:10.

\subsubsection{Natural Dyeing Process:}

Dyeing carried out by exhaust method in Gyrowash lab sample dyeing machine (James H. Heal, England). 100cc Annatto (Bixa orellana) dye was used for each of $10 \mathrm{gm}$ mordanted sample fabric as dyeing medium. Samples were dyed with the extract dye solution ratio of material: liquor $1: 10$ at $100^{\circ} \mathrm{C}$ for 60 minutes. Some of the samples were dyed with $5 \mathrm{gm} / \mathrm{L}$ Glauber salt and some are not. Then the dye bath was cooled at $40^{\circ} \mathrm{C}$. Samples were washed at room temperature and samples were squeezed and air dried in flat dryer machine (MESDAN, Italy). Then some samples were washed with $0.5 \mathrm{~g} / \mathrm{L}$ ISO standard soap about the material: liquor ratio $1: 10$ at $70^{\circ} \mathrm{C}$ for 10 minutes.

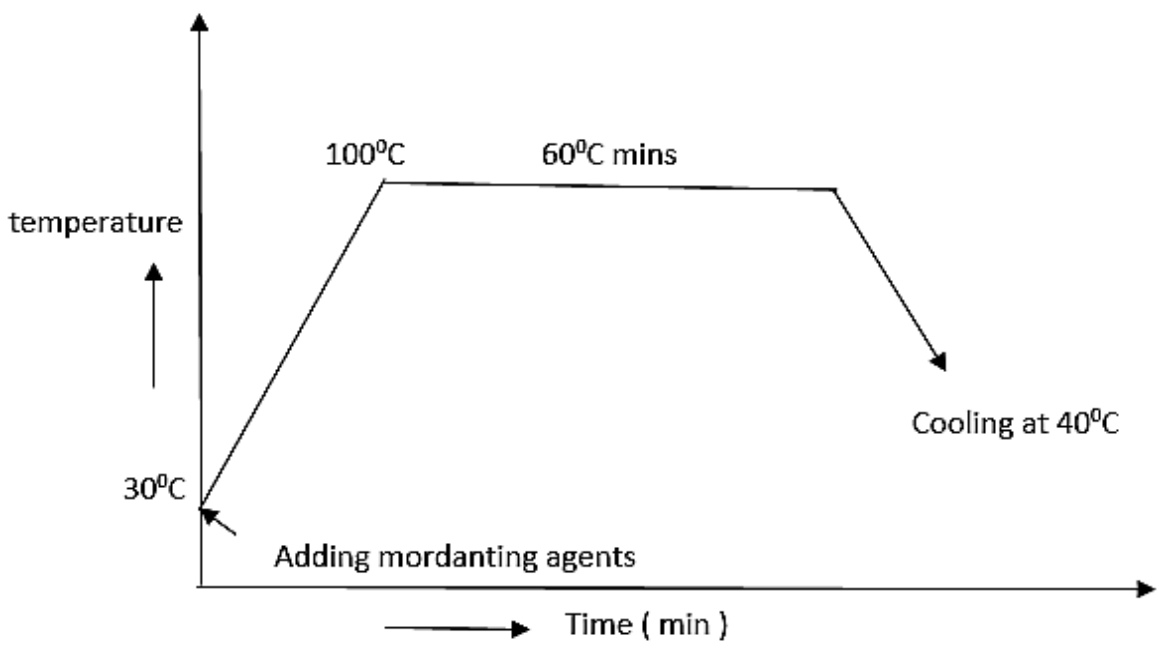

Figure 3. Process curve of pre-mordanting

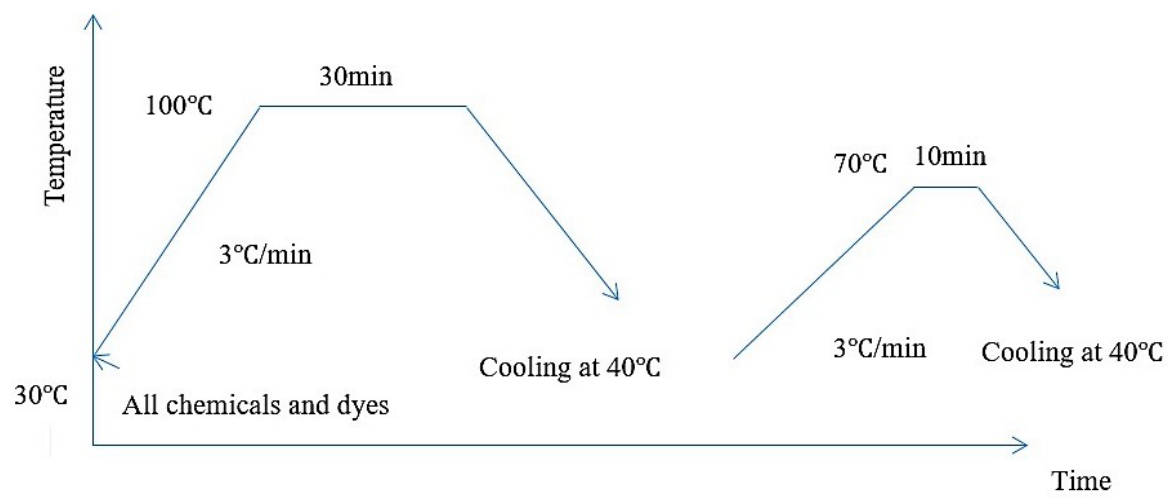

Figure 4. Dyeing Curve for natural dyeing (Bixa orellana)

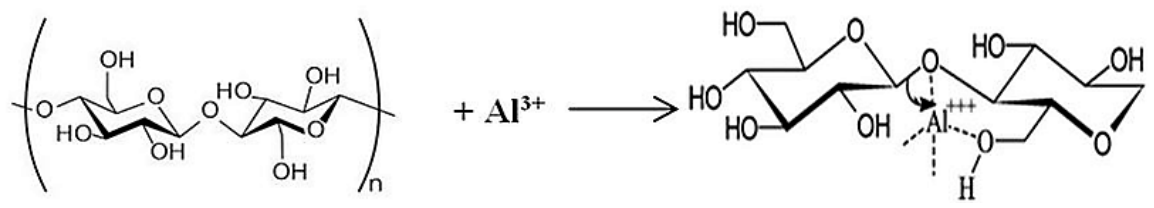

Figure 5. Coordination-bond-formation-during-mordanting-of-cotton-with-alum 


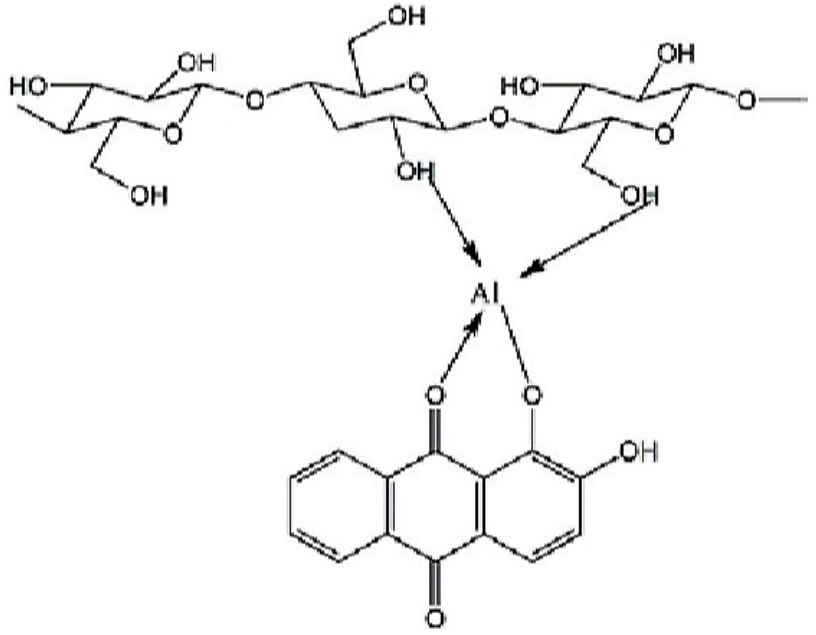

Figure 6. The connection among cellulose, mordant and natural dye

\subsection{Determination of Color Fastness}

In order to evaluate various color fastness properties of the selected dyed fabric, standard methods were employed. Color fastness to wash, rubbing (dry and wet), water, perspiration, was accessed by using grey scale of color change and staining according to ISO $105 \mathrm{C04}$ [9], ISO 105 X12 [10], ISO 105 E01 [11], ISO 105 E04 [12] respectively.

\subsection{Determination of Color Strength}

The color strength of the dyed samples was measured by Data-color Spectroflash SF 650X with the following settings:

i Illuminant D65,

ii Large area view (LUV),

iii Specular included and

iv CIE 1964 supple-mental standard observer $\left(10^{0}\right.$ observer).

The K/S value of the dyed samples was measured by data color spectrophotometer based on Kubelka-Munk theory $[\mathbf{1 3 , 1 4 ]}$ which gives the relationship between K/S and $\mathrm{R}$ as mentioned below,

$$
\mathrm{K} / \mathrm{S}=(1-\mathrm{R})^{2} / 2 \mathrm{R}
$$

where $\mathrm{R}$ is an incident light from the material, $\mathrm{K}$ and $\mathrm{S}$ is absorption and scattering co-efficient of the dyed fabric respectively. Each sample was folded twice to give an opaque view with four plies and the $\mathrm{K} / \mathrm{S}$ value was measured automatically.

\section{Result and Discussion}

\subsection{Effect of Metallic Mordants in Dye Fixation}

In this investigation cotton fabric samples were dyed and finished in various conditions. Several metallic salts were applied as mordanting agents to intensify the natural dye fixation. Influences of electrolyte for Color strength (CS) of selected samples were also examined [15] [16].

Several metallic salts were used as mordanting agents to intensify the dye fixation and color strength as well. Iron(II) Sulphate, Iron(III) Chloride, Cu(II) Sulphate and Alum were used as mordanting agents separately. All selected samples were dyed at $100^{\circ} \mathrm{C}$ for 60 minutes.

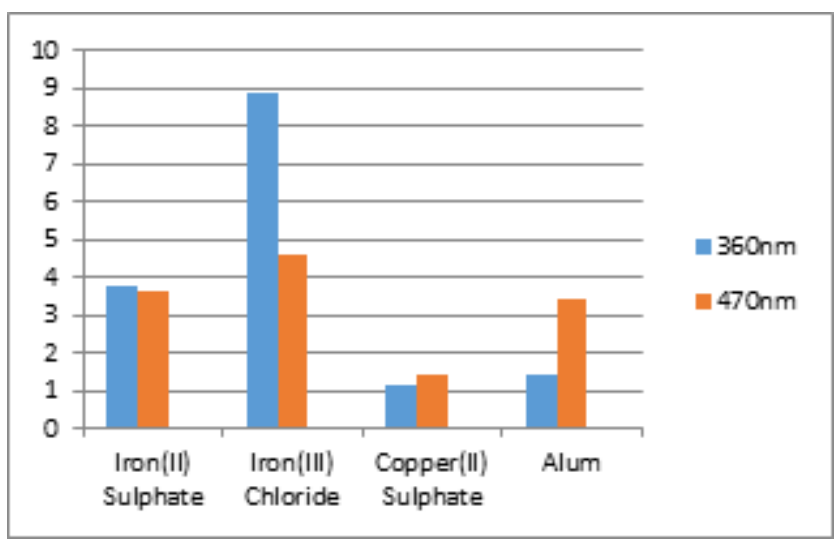

Figure 7. Effect of K/S values on mordanting agents dyed without salt and without hot wash

Above figure depicts two type K/S values. The K/S values at $360 \mathrm{~nm}$ and the $\mathrm{K} / \mathrm{S}$ values are at $470 \mathrm{~nm}$. These values are gained from the dyed samples without salt and without hot wash. Here maximum exhibit K/S value 8.9 at wavelength $360 \mathrm{~nm}$. For Iron(II) Sulphate, Iron(III) Chloride, Copper(II) Sulphate and Alum K/S value is 3.8, 8.9, 1.12 and 1.4 respectively at $360 \mathrm{~nm}$ and 3.6, 4.6, 1.45 and 3.4 respectively at $470 \mathrm{~nm}$. For Iron (II) Sulphate and Iron(III) Chlorides samples exhibit better color strength. Conversely, Copper(II) Sulphate has less fixation ability than Iron \& Alum,. But for Iron uneven shade is yield. So, in this investigation Alum is applied as standard mordants.

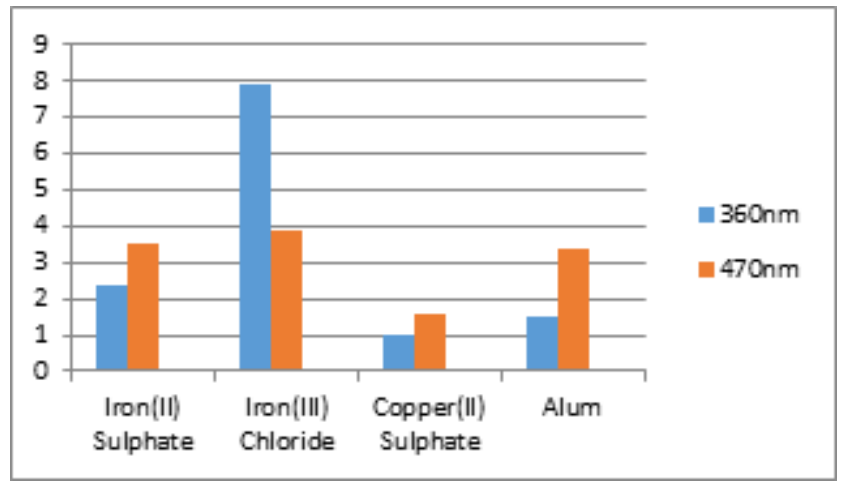

Figure 8. Effect of K/S values dyed with salts but without hot wash

Above figure illustrates that in addition of salts K/S values start to plummet for Iron(II) Sulphate and Iron(III) Chloride. On the contrary, the K/S value of Copper(II) 
Sulphate and Alum increase at 470nm.

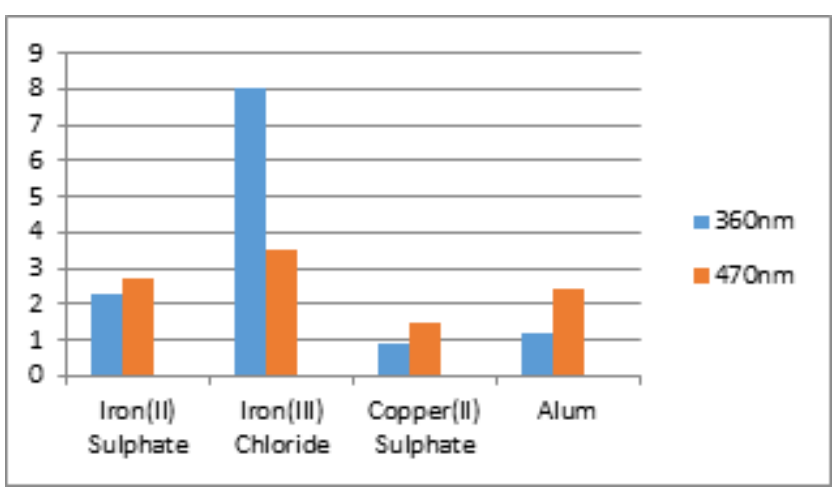

Figure 9. Effect of K/S values dyed with salt and with hot wash

Above figure illustrates that in addition of salts, K/S values decrease quickly for Iron(II) Sulphate, Iron(III) Chloride and Alum when hot wash is done but for Copper(II) Sulphate K/S value decreases slowly. So Copper(II) Sulphate is the best mordant.

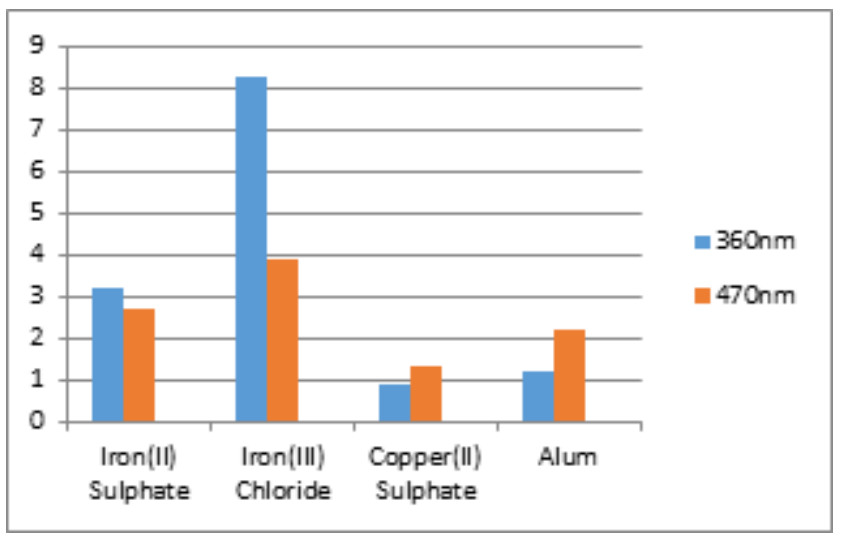

Figure 10. Effect of K/S values dyed without salt but with hot wash

Above figure illustrates that samples finished with hot wash when dyed without salt, overall K/S values increase for Iron(II) Sulphate, Iron(III) Chloride but for Copper(II) Sulphate K/S value decreases at 470nm and increases at $360 \mathrm{~nm}$ and for Alum as well as K/S value same at 360nm and decreases at 470nm. As Iron gives uneven dyeing so Copper(II) Sulphate is the best mordant.

Table 2. Effect of metallic salts for samples K/S value evaluation

\begin{tabular}{|c|c|c|c|c|c|c|c|c|}
\hline & \multicolumn{2}{|c|}{ A } & \multicolumn{2}{|c|}{ B } & \multicolumn{2}{|c|}{ C } & \multicolumn{2}{|c|}{ D } \\
\hline & at $360 \mathrm{~nm}$ & at $470 \mathrm{~nm}$ & at $360 \mathrm{~nm}$ & at 470nm & at $360 \mathrm{~nm}$ & at 470nm & at $360 \mathrm{~nm}$ & at $470 \mathrm{~nm}$ \\
\hline $\begin{array}{l}\text { without salt and } \\
\text { without hot wash }\end{array}$ & 3.8 & 3.6 & 8.9 & 4.6 & 1.12 & 1.45 & 1.4 & 3.4 \\
\hline $\begin{array}{l}\text { with salts and } \\
\text { without hot wash }\end{array}$ & 2.4 & 3.5 & 7.9 & 3.9 & 1.0 & 1.6 & 1.5 & 3.4 \\
\hline $\begin{array}{l}\text { with salt and } \\
\text { with hot wash }\end{array}$ & 2.2 & 2.8 & 8 & 3.5 & 0.8 & 1.5 & 1.2 & 2.4 \\
\hline $\begin{array}{l}\text { without salt and } \\
\text { with hot wash }\end{array}$ & 3.2 & 2.7 & 8.2 & 3.9 & 0.9 & 1.3 & 1.2 & 2.1 \\
\hline
\end{tabular}

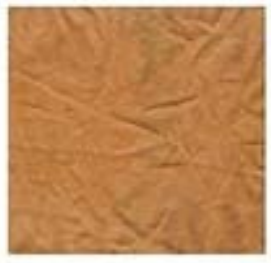

$\mathrm{FeSO}_{4}+$ Gluber Salt
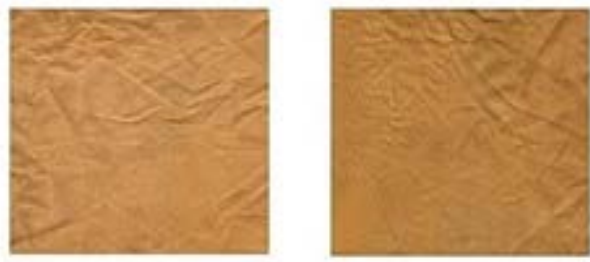

$\mathrm{FeSO}_{4}+$ Without Salt $\quad \mathrm{FeCl}_{3}+$ Gluber Salt
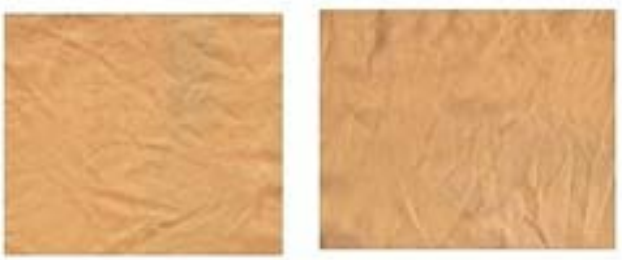

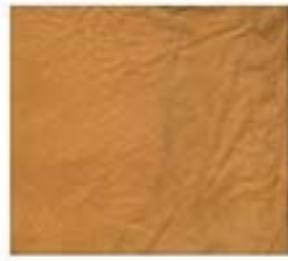

$\mathrm{FeCl}_{3}+$ Without Gluber Salt
$\mathrm{CuSO}_{4}+$ Without Salt

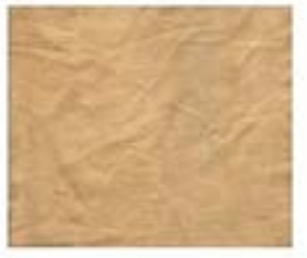

Potash alam + Salt

Potash alam + Without Salt

$\mathrm{CuSO}_{4}+\mathrm{Salt}$

Figure 11. Appearance of the Dyed samples with various mordanting agents and in different conditions 


\subsection{Impact of Various Mordanting Agents on Color Fastness Properties}

\subsubsection{Color Fastness to Wash}

Following table express that change in color for control samples is very good. All mordanted samples shows very good to excellent result for change in color. In case of staining in color, control samples exhibit fair result toward di-acetate and polyester. In addition, control samples exhibit fair to moderate result toward polyamide and wool.

Table 3. Ratting of various Mordanting agents on Color fastness to wash

\begin{tabular}{|c|c|c|c|c|c|c|c|}
\hline \multirow{2}{*}{ Reagents } & \multirow{2}{*}{ Change in Color } & \multicolumn{5}{|c|}{ Staining in color } \\
\cline { 3 - 8 } & & Acetate & Cotton & Nylon & Polyester & Acrylic & Wool \\
\hline $\mathrm{FeSO}_{4}+$ Salt + Hot wash & 2 & $4-5$ & 2 & $4-5$ & $4-5$ & $4-5$ & 4 \\
\hline $\mathrm{FeSO}_{4}+$ Without salt + Hot wash & $1-2$ & $4-5$ & 2 & $4-5$ & $4-5$ & $4-5$ & $4-5$ \\
\hline $\mathrm{FeCl}_{3}+$ Salt + Hot wash & $2-3$ & 4 & 2 & 4 & $4-5$ & $4-5$ & 4 \\
\hline $\mathrm{FeCl}_{3}+$ Without salt + Hot wash & $1-2$ & $4-5$ & 2 & 4 & $4-5$ & $4-5$ & 4 \\
\hline $\mathrm{CuSO}_{4}+$ Salt+Hot wash & $1-2$ & $4-5$ & 4 & $4-5$ & $4-5$ & $4-5$ & $4-5$ \\
\hline $\mathrm{CuSO}_{4}+$ Without salt + Hot wash & 1 & $4-5$ & 4 & $4-5$ & $4-5$ & $4-5$ & $4-5$ \\
\hline Alum + Salt + Hot wash & $2-3$ & 4 & 2 & 4 & $4-5$ & $4-5$ & 4 \\
\hline Alum + Without salt + Hot wash & 2 & $4-5$ & 2 & 4 & $4-5$ & $4-5$ & 4 \\
\hline
\end{tabular}

\subsubsection{Color Fastness to Rubbing}

Following table represents color fastness to dry and wet rubbing. All mordanted samples exhibit excellent to good dry rubbing fastness and exhibit very good to fair wet rubbing fastness.

Table 4. Ratting of Mordanting agents on Color fastness to Rubbing of dyed samples

\begin{tabular}{|c|c|c|}
\hline Reagents & Dry Rubbing & Wet Rubbing \\
\hline Iron(II) Sulphate + Glauber salt & 5 & $3-4$ \\
\hline Iron(II) Sulphate + no salt & 5 & $2-3$ \\
\hline Iron(III) Chloride + Glauber salt & 5 & $2-3$ \\
\hline Iron(III) Chloride + no salt & $4-5$ & 5 \\
\hline Copper(II) Sulphate + Glauber salt & 5 & $4-5$ \\
\hline Copper(II) Sulphate + no salt & 5 & 4 \\
\hline Alum + Glauber salt & 5 & $4-5$ \\
\hline Alum + no salt & 5 & \\
\hline
\end{tabular}

\subsubsection{Color Fastness to Perspiration (Acid)}

Table 5. Color Fastness to Perspiration (Acid)

\begin{tabular}{|c|c|c|c|c|c|c|c|}
\hline \multirow{2}{*}{ Reagents } & \multirow{2}{*}{ Change in Color } & \multicolumn{6}{|c|}{ Staining in color } \\
\hline & & Acetate & Cotton & Nylon & Polyester & Acrylic & Wool \\
\hline $\mathrm{FeSO}_{4}+$ Salt+Hot wash & 1 & 4 & $2-3$ & 3 & $4-5$ & $4-5$ & 4 \\
\hline $\mathrm{FeSO}_{4}+$ No salt + Hot wash & 1 & 4 & 3 & 3-4 & $4-5$ & $4-5$ & 4 \\
\hline $\mathrm{FeCl}_{3}+$ Salt + Hot wash & $1-2$ & $3-4$ & $3-4$ & 3 & $4-5$ & $4-5$ & $3-4$ \\
\hline $\mathrm{FeCl}_{3}+$ No salt + Hot wash & 2 & 3-4 & 3 & 3 & $4-5$ & $4-5$ & $3-4$ \\
\hline $\mathrm{CuSO}_{4}+$ Salt+ Hot wash & 1 & 4 & $2-3$ & $3-4$ & $4-5$ & $4-5$ & 3 \\
\hline $\mathrm{CuSO}_{4}+$ No salt + Hot wash & 1 & 4 & 3 & 3-4 & $4-5$ & $4-5$ & 3 \\
\hline Alum + Salt + Hot wash & 1 & 4 & 3 & 3 & $4-5$ & $4-5$ & 4 \\
\hline Alum + No salt + Hot wash & 1 & $3-4$ & $2-3$ & 3 & 4 & $4-5$ & 4 \\
\hline
\end{tabular}




\subsubsection{Color Fastness to Perspiration (Alkali)}

Table 6. Color Fastness to Perspiration (Alkali)

\begin{tabular}{|c|c|c|c|c|c|c|c|}
\hline \multirow{2}{*}{ Reagents } & \multirow{2}{*}{ Change in Color } & \multicolumn{6}{|c|}{ Staining in color } \\
\hline & & Acetate & Cotton & Nylon & Polyester & Acrylic & Wool \\
\hline $\mathrm{FeSO}_{4}+$ Salt + Hot wash & $1-2$ & 4 & 2 & 4 & $4-5$ & $4-5$ & 4 \\
\hline $\mathrm{FeSO}_{4}+$ No salt + Hot wash & $1-2$ & 4 & $2-3$ & 4 & $4-5$ & $4-5$ & 4 \\
\hline $\mathrm{FeCl}_{3}+$ Salt+Hot wash & 2 & $3-4$ & $2-3$ & $3-4$ & $4-5$ & $4-5$ & $3-4$ \\
\hline $\mathrm{FeCl}_{3}+$ No salt + Hot wash & $2-3$ & $3-4$ & $2-3$ & $3-4$ & $4-5$ & $4-5$ & $3-4$ \\
\hline $\mathrm{CuSO}_{4}+\mathrm{Salt}+\mathrm{Hot}$ wash & 3 & 4 & $2-3$ & 4 & $4-5$ & $4-5$ & 3 \\
\hline $\mathrm{CuSO}_{4}+$ No salt + Hot wash & 3 & 4 & 2 & 4 & $4-5$ & $4-5$ & 3 \\
\hline Alum + Salt + Hot wash & $2-3$ & 4 & $2-3$ & 4 & $4-5$ & $4-5$ & 4 \\
\hline Alum + No salt + Hot wash & $2-3$ & $3-4$ & $2-3$ & 4 & 4 & $4-5$ & 4 \\
\hline
\end{tabular}

\subsubsection{Color Fastness to Water}

Table 7. Color Fastness to Water

\begin{tabular}{|c|c|c|c|c|c|c|c|}
\hline \multirow{2}{*}{ Reagents } & \multirow{2}{*}{ Change in Color } & \multicolumn{6}{|c|}{ Staining in color } \\
\hline & & Acetate & Cotton & Nylon & Polyester & Acrylic & Wool \\
\hline $\mathrm{FeSO}_{4}+$ Salt + Hot wash & 2 & 4 & $2-3$ & $2-3$ & $4-5$ & $4-5$ & 4 \\
\hline $\mathrm{FeSO}_{4}+$ No salt + Hot wash & 2 & 4 & $2-3$ & $2-3$ & $4-5$ & $4-5$ & 4 \\
\hline $\mathrm{FeCl}_{3}+$ Salt + Hot wash & $3-4$ & $3-4$ & $3-4$ & 3 & $4-5$ & $4-5$ & $3-4$ \\
\hline $\mathrm{FeCl}_{3}+$ No salt + Hot wash & 3 & $3-4$ & 3 & 3 & $4-5$ & $4-5$ & $3-4$ \\
\hline $\mathrm{CuSO}_{4}+$ Salt + Hot wash & $3-4$ & 4 & $2-3$ & 3 & 4 & $4-5$ & $3-4$ \\
\hline $\mathrm{CuSO}_{4}+$ No salt + Hot wash & $3-4$ & 4 & $2-3$ & 3 & $4-5$ & $4-5$ & $3-4$ \\
\hline Alum + Salt + Hot wash & $2-3$ & 4 & 3 & $2-3$ & $4-5$ & $4-5$ & 4 \\
\hline Alum + No salt + Hot wash & $2-3$ & $3-4$ & $2-3$ & 3 & 4 & $4-5$ & 4 \\
\hline
\end{tabular}

\section{Conclusions}

The experimental data obtained in this work proved that Samples were dyed with salt, without salt and washed with standard soap, without standard soap. Color strength of the dyed samples for different dyeing condition was assessed by means of K/S value. Best color strength was yield for the sample which was mordanted with $\mathrm{FeCl}_{3}$, dyed without Glauber salt and washed without standard soap. But the samples which were mordanted with $\mathrm{CuSO}_{4}$ exhibit best color fastness properties. So, $\mathrm{CuSO}_{4}$ can be presumed as best mordanting agents. Results of all tested color fastness were very good to excellent. Only color fastness to rubbing was fair to good for natural dye. So, this technology could be employed where fabric will be exposed in less rubbing actions. This reports forecast developing a sustainable technology for effective utilization of Bixa orellana seed for coloration of cotton fabric. Critical assessment of all tested properties of colored samples reveals, this technology can be commercially implemented by considering few limitations.

\section{Acknowledgements}

The authors would like to thank to Md. Abdullah $\mathrm{Al}$ Mamun, Assistant Professor, Department of Textile
Engineering, MBSTU, Bangladesh. Also thanks to all teachers of Textile Engineering Department, MBSTU, Bangladesh for their good support, help and coordination at all points during data collection.

\section{REFERENCES}

[1] Pezzolo DB (2007), Tecidos: história, tramas, tipos e usos, São Paulo, Brazil: Senac Publishing.

[2] Manley JB, Anastas PT, Cue BW (2008), Frontiers in Green Chemistry: meeting the grand challenges for sustainability in R\&D and manufacturing, Journal of Cleaner Production, 16, 743-750.

[3] Mirjalili M, Nazarpoor K and Karimi L (2011), Eco-friendly dyeing of wool using natural dye from weld as co-partner with synthetic dye, Journal of Cleaner Production, 19, 1045-1051.

[4] Bechtold T, Turcanu A, Ganglberger B and Geissler B (2003), Natural dyes in modern textile dyehouses - how to combine experiences of two centuries to meet the demands of the future?, Journal of Cleaner Production, 11, 499-509.

[5] Kiran Sachan \& Kapoor V P, Colourage, Eucalyptus bark dye: Standardization of extraction and eco- friendly dyeing profiles, 41 (2004). 
[6] Islam-ul S, Rather LJ, Shahid M, Khan MA and Mohammad F (2014), Study the effect of ammonia post-treatment on color characteristics of annatto-dyed textile substrate using reflectance Spectrophotometry, Industrial Crops and Products, 59, 337-342.

[7] Orska-Gawrys, J., Surowiec, I., Kehl, J., Rejniak, H., Urbaniak-Walczak, K. and Trojanowicz, M. (2003): "Identification of natural dyes in archeological Coptic textiles by liquid chromatography with diode array detection”, Journal of Chromatography A, 989 239-248.

[8] Tocchini, L. y Mercadante, A.Z. (2001): "Extraçao e determinaçao, por CLAE, de Bixina e Norbixina em colouríficos”, Cienc. Tecnol. Aliment. Campinas, 21(3) 310-313.

[9] AATCC.2013 AATCC Test Method 61-2013 colorfastness to laundering: Accelerated.
[10] AATCC.2013 AATCC Test Method 8-2013 colorfastness to Rubbing.

[11] AATCC.2008 AATCC Test Method 107-2013 colorfastness to water.

[12] AATCC.2006 AATCC Test Method 15-2013 colorfastness to perspiration.

[13] Kubelka P. In part I, JOSA, 1948, Vol.38, no.5, p.448.

[14] Kubelka P. In part II, JOSA, 1954, Vol.44, no.4, p.330.

[15] Shalini Chandravanshi, Santosh K. Upadhyay \& Abha Bhargava, "Effect of ironic surfactants on the absorption of Quercus infectoria natural dye on cotton fiber: A kinetic study”. Journal of dispersion Science and technology, Vol.35, No.10, pp1427-1433, 2014.

[16] Vickerstaff, Thomas.” Physical chemistry of dyeing”1954. 